\title{
Natürlicher grammatischer Wandel im System aspektueller Oppositionen des Russischen*
}

\begin{abstract}
Zusammenfassung
Im Frühaltrussischen koexistierten die drei miteinander konkurrierenden aspektuellen Oppositionen, nämlich die alten indoeuropäischen Aspekte (der imperfektive, der perfektive und der perfektische), die alte slavische Opposition Nicht-Iterativität/Iterativität und die neuen slavischen Aspekte ( $=$ Opposition Imperfektivität/Perfektivität). Im Laufe der Sprachentwicklung wurden die ersten zwei Oppositionen durch die dritte Opposition verdrängt. Der Verlauf und die Mechanismen dieser Entwicklung werden dargestellt und auf der Grundlage des Konzepts des natürlichen grammatischen Wandels erklärt. Es werden Markiertheitsprinzipien betrachtet, die den natürlichen grammatischen Wandel determinieren. Diese Prinzipien werden als generelle Faktoren typologischen Wandels angesehen, mit deren Hilfe die grammatischen Veränderungen im Sprachsystem erklärt werden können. Die Ausprägung der neuen slavischen Aspekte und die immer stärker werdende Einbeziehung der Aspekte in das gesamte Verbalsystem haben entscheidend zur Herausbildung des neuen reduzierten aspektsensitiven Tempussystems beigetragen.
\end{abstract}

\section{Einführung: Theoretische Grundlagen}

Die historische Entwicklung der aspektuellen Oppositionen wird auf der theoretischen Grundlage des Konzepts der Markierheit $(=$ Natürlichkeit $=$ Präferenz $)$ und des Konzepts des natürlichen grammatischen Wandels in der Natürlichen Grammatik behandelt.

Das Konzept der Markiertheit (vgl. z.B. Wurzel 1998: 62-65; Mayerthaler 1981: 911) baut auf dem Begriff der linguistischen Komplexität auf, die die Sprachkapazität des Sprachträgers belastet: Stärker markierte grammatische Erscheinungen belasten die Sprachkapazität mehr als ihre schwächer markierten Gegenstücke. Die Markiertheit wird folglich unter Rekurs auf biologisch-neurologische Gegebenheiten des Sprachträgers bestimmt. Sie ist ein Teil der menschlichen Sprachfähigkeit und gehört zur sprachlichen Ausstattung des Menschen. Die universellen Prinzipien der Markiertheit (= Natürlichkeitsprinzipien (Wurzel 1984) = preference laws (Vennemann 1988)) bestimmen, welche sprachlichen Struktureigenschaften, die durch die strikten (= absoluten) Prinzi-

* Die vorliegende Untersuchung ist im Rahmen des von der Deutschen Forschungsgemeinschaft geförderten Projekts „Markiertheitsrelationen in Tempus-Systemen slavischer Sprachen“ entstanden. Den Leitern des Projekts Prof. Dr. Werner Winter und Prof. Dr. Wolfgang Ulirich Wurzel danke ich ganz herzlich für die langjährige großzügige und tatkräftige fachliche und menschliche Unterstützung meiner Arbeit. Der Abschnitt 5 dieses Beitrags wurde im Zentrum für Allgemeine Sprachwissenschaft am 22. Februar 2001 als Vortrag unter dem Titel ,Die Entwicklung der-yva-/-iva-Bildungen im Russischen: Evidenzen für den natürlichen grammatischen Wandel" vorgestellt. Bei allen an der Aussprache beteiligten Kollegen möchte ich mich an dieser Stelle für die interessante und anregende Diskussion herzlich bedanken. Für dic sorgfältige Durchsicht des Manuskripts und zahlreiche kritische Bemerkungen danke ich ganz herzlich Frau Dr. Gerda Klimonow. Verbliebene Fehler und Mängel gehen selbstverständlich zu meinen Lasten. 
pien der universellen Grammatik vorgegeben sind, unmarkiert bzw. natürlich bzw. präferent und welche markiert bzw. nicht-natürlich bzw. nicht-präferent sind. Diese Prinzipien legen die Markiertheitsrelationen zwischen grammatischen Einheiten gleicher Klasse in bezug auf bestimmte Parameter fest: Eine grammatische Erscheinung $\mathrm{G}_{\mathrm{j}}$ ist hinsichtlich des Markiertheitsparameters $\mathrm{M}_{\mathrm{i}}$ umso schwächer markiert, in je stärkerem Grade sie die Eigenschaft $\mathrm{E}_{\mathrm{k}}$ hat (Wurzel 1994: 38). Auf diese Weise wird die systematische Asymmetrie in der Verwendung von grammatischen Mitteln erklärt, die in der Struktur aller Sprachen und in der Sprachentwicklung zu beobachten ist. Diese Prinzipien bilden eine spezifische Klasse von Universalien, die man als Bewertungsuniversalien bezeichnen kann. Die Gesamtheit der Markiertheitsprinzipien konstituiert die Markiertheitstheorie.

Jede Ebene des Sprachsystems verfügt über ihre eigenen Markiertheitsverhältnisse. Dementsprechend werden phonologische, morphologische, syntaktische und semantische Markiertheit grammatischer Einheiten unterschieden. Die phonologische Markiertheit beruht auf der artikulatorischen und/oder perzeptiven Komplexität. Die morphologische und die syntaktische Markiertheit basiert auf der semiotischen Komplexität, d.h. auf der Komplexität der Zeichenverhältnisse. Die semantische Markiertheit grammatischer Einheiten ist in deren kognitiver Komplexität begründet.

Für das Verständnis der Markiertheit ist entscheidend, dass diese nicht mit Merkmalhaftigkeit gleichgesetzt werden kann. Die Merkmalhaftigkeit bezieht sich auf das Vorhandensein bzw. Nicht-Vorhandensein bestimmter Merkmale in sprachlichen Einheiten. Die Merkmalhaftigkeit einerseits und die Markiertheit andererseits sind nicht notwendigerweise identisch. Die altrussischen Verben bildeten normalerweise die 3. P.Sg. und Pl. mit

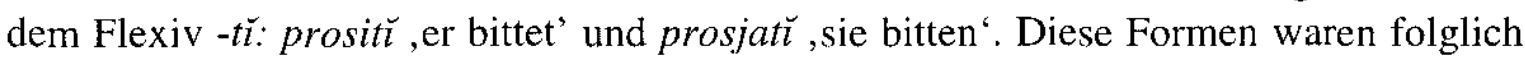
merkmalhaft. Es existierten aber auch einige merkmallose Formen mit Zero-Endung vom Typ prosi ,er bittet" und prosja ,sie bitten'. Die merkmalhafte Endung - $t \check{l}$ in der 3.

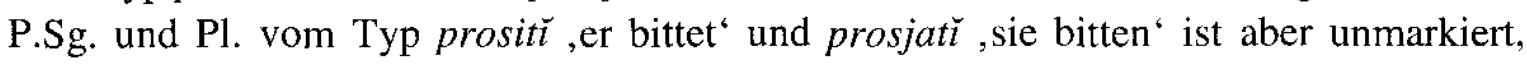
weil sie systemangemessen, d.h. typisch, normativ oder natürlich ist. Die merkmallose Zero-Endung vom Typ prosi ,er bittet" und prosja , sie bitten' ist dagegen markiert, weil sie nicht systemangemessen, d.h. speziell, nicht normativ oder nicht natürlich ist.

Die Markiertheitstheorie ist ein unentbehrlicher Bestandteil des Konzepts des natiirlichen grammatischen Wandels, d.h. der Theorie des Sprachwandels, die den grammatisch initiierten Wandel erklären will. Die Geschichte der russischen Aspekte und die Einwirkung der Aspekte auf die Tempusentwicklung werden unter dem Blickwinkel der Theorie des natürlichen grammatischen Wandels betrachtet (vgl. Wurzel 1994, Vennemann 1988). Die grammatischen Veränderungen im Sprachsystem verlaufen nach generellen Entwicklungstendenzen, die durch die Wirkung der Markierheitsprinzipien determiniert sind. Die grundlegende Annahme des Markiertheitskonzepts zum Sprachwandel ist als Prinzip des natürlichen grammatischen Wandels formuliert. Diesem Prinzip zufolge verläuft grammatisch initiierter Wandel in Richtung der Ersetzung von hinsichtlich eines bestimmten Markiertheitsparameters stärker markierten grammatischen Einheiten durch hinsichtlich dieses Parameters schwächer markierte grammatische Einheiten. Die einzelnen Markiertheitsprinzipien bestimmen, was markiert ist und damit gemäß dem Prinzip des natürlichen grammatischen Wandels als Kandidat für den Abbau auftritt. Das Wesen jedes natürlichen grammatischen Wandels ist es, die Markiertheit grammatischer Erschei- 
nungen im Sprachsystem abzubauen. Die den Markiertheitsabbau steuernden Prinzipien legen die Prioritäten zwischen miteinander konkurrierenden Veränderungstendenzen fest. Das Prinzip des geordneten oder stufenweisen Markiertheitsabbaus regelt die Reihenfolgen der Wandelerscheinungen: Stärker markierte Erscheinungen werden vor ihren schwächer markierten Pendants vom Wandel erfasst. Das Prinzip der Regelung des Markiertheitsabbaus durch die Hierarchie der Markiertheitsprinzipien legt die Prioritäten in der Anwendung mehrerer Prinzipien aufgrund ihrer Stellung in der Hierarchie der Markiertheitsprizipien fest: Ein in der Hierarchie höher eingeordnetes Prinzip (z.B. das Prinzip der Systemangemessenheit) wirkt stärker als ein in der Hierarchie niedriger eingeordnetes Prinzip (z.B. das Prinzip des konstruktionellen Ikonismus). Die grammatischen Universalien und die einzelsprachlichen Systeme bedingen die Veränderungsmöglichkeiten natürlicher Sprachen und schränken sie zugleich auf verschiedene Weise ein. Diese Faktoren sind relevant für die Erklärung von grammatisch initiiertem Wandel. Die Interaktion der einzelnen, den grammatischen Sprachwandel determinierenden Prinzipien ist noch nicht hinreichend erforscht. Die Theorie des natürlichen Sprachwandels gibt eine Erklärung für die generellen Tendenzen der Entwicklung des Sprachsystems und liefert damit linguistisch begründete Prognosen über die Richtung der potenziellen sprachlichen Veränderungen.

Der Umbau des Tempussystems und andere tiefgreifende Veränderungen im russischen Verbalsystem wurden durch die Ausprägung der neuen slavischen Aspekte ausgelöst. Die Aspekte sind im Laufe der Sprachentwicklung zur eigentlichen Grundlage des gesamten russischen Verbalsystems geworden. Der Übergang von der Entwicklung des Aspektsystems zur Entwicklung des Tempussystems ist fließend. Die Ersetzung der alten indoeuropäischen Aspekte durch die neuen slavischen Aspekte im präteritalen Bereich betrifft eher die Veränderungen sowohl im Aspektsystem als auch im Tempussysstem. Ich betrachte deshalb die Entwicklung der Aspekte und die Entwicklung der Tempora in den einschlägigen Abschnitten 4 und 5 parallel.

\section{Koexistenz und Interaktion der drei aspektuellen Oppositionen im Frühaltrussischen}

Ich gehe von der Annahme aus, dass im Frühaltrussischen drei miteinander konkurrierende aspektuelle Oppositionen, nämlich die alten indoeuropäischen Aspekte (der imperfektive, der perfektive und der perfektische), die alte slavische Opposition Nicht-Iterativität/ Iterativität und die neuen slavischen Aspekte (= Opposition Imperfektivität/ Perfektivität) koexistierten. Das Altrussische war folglich sehr reich an aspektuellen Differenzierungen.

Die alten indoeuropäischen Aspekte waren auf den präteritalen Bereich beschränkt und fanden ihren formalen Ausdruck in den Verbalendungen, die gleichzeitig Tempusund Aspektmarker waren, vgl. die Gegenüberstellung zwischen dem Imperfekt bzw. dem imperfektiven Aspekt vom Typ vedjach $\breve{u}$,ich führte', dem Aorist bzw. dem perfektiven Aspekt vom Typ vedochŭ, ich habe geführt" und dem Perfekt bzw. dem perfektischen Aspekt vom Typ jesmi velŭ, ich habe geführt". Als Ausdruck der semantischen Basis der 
alten indoeuropäischen Aspekte dienten im Altrussischen die Oppositionen [+STATISCH] beim Perfekt vs. [-STATISCH] beim Imperfekt und beim Aorist, sowie [+DURATIV] des Imperfekts vs. [-DURATIV] des Aorists. Die beiden synthetischen Formen der Vergangenheit (das Imperfekt und der Aorist) waren im Altrussischen auf den Infinitivstamm festgelegt und hatten ein gemeinsames Suffix $-s-/-c h-/-s ̌$ - als Marker der Vergangenheit. Diese beiden Tempora hatten gesonderte Personalendungen und unterschiedliche Themavokale. Das Imperfekt trat als markiertes Glied der Opposition Imperfekt vs. Aorist auf. Es hatte ein Formans $-a$-, das in den Formen des Aorists fehlte, und es drückte die Bedeutung der Durativität der Handlung, d.h. den unbegrenzten Verlauf einer einzigen Handlung oder einer Reihe von Handlungen aus.

Die neue slavische Kategorie des imperfektiven Aspekts (ipf. A.) und des perfektiven Aspekts (pf. A.) hatte eine ganz andere formale Basis, nämlich die Stammaffigierung, vgl. die Gegenüberstellung der Aspektstämme mit und ohne Imperfektivierungssuffixe vom Typ sŭbirajeť (ipf. A.), er sammelt - sŭbereť (pf. A.), er wird sammeln“ und zwischen präfixlosen und präfigierten Aspektstämmen vom Typ neseť (ipf. A.) ,er trägt' - poneseť (pf. A.), er wird tragen'. Die Semantik der neuen slavischen Aspekte unterscheidet sich auch von der Bedeutung der alten indoeuropäischen Aspekte. Die Perfektiva (Pf.), die die Ganzheitlichkeit oder Totalität des Prozesses signalisieren (d.h. die Anfangsgrenze und die Endgrenze einschließen), werden als markiertes, d.h. komplexeres Glied der aspektuellen Opposition angesehen, während die Imperfektiva (Ipf.), die die Nicht-Ganzheitlichkeit oder Nicht-Totalität des Prozesses bezeichnen (d.h. die Anfangsgrenze und die Endgrenze ausschließen) als unmarkiertes, d.h. weniger komplexes Glied dieser Opposition betrachtet werden. Im Altrussischen kreuzten sich die alten und die neuen Aspektoppositionen: Es existierten das imperfektive und das perfektive Imperfekt sowie der perfektive und der imperfektive Aorist. Es bestand allerdings eine Affinität zwischen den beiden Typen aspektueller Systeme: der Aorist (vom Typ postaviša , sie haben gestellt') wurde hauptsächlich von perfektiven Stämmen (vom Typ postaviti ,stellen') und das Imperfekt (vom Typ postavljachu(ti) , sie stellten') hingegen von imperfektiven Stämmen (vom Typ postavljati, stellen') gebildet. Die Bildung und der Gebrauch des imperfektiven Aorists und des perfektiven Imperfekts waren mit einigen Restriktionen verbunden (vgl. Abschn. 4.2).

Neben den alten indoeuropäischen und den neuen slavischen Aspekte existierte im Altrussischen die alte slavische Opposition Nicht-Iterativität/Iterativität. Die iterativen Verben wurden im Altrussischen von imperfektiven Simplizia mit Hilfe der Suffixe $-a-$, -ja-, -va- und den Erweiterungen von -va-: -ava-, -ova-, -eva- gebildet: pǔlzti ,kriechen" - pŭlzati ,umherkriechen', sěti ,säen' - sějat ,zu säen pflegen', biti, schlagen ‘ - bivati ,zu schlagen pflegen', dělati ,tun, machen“ - dělovati ,zu tun pflegen“. Die Gegenüberstellung Determiniertheit/Indeterminiertheit bei den Bewegungsverben vom Typ letěti ,fliegen “ - lětati ,umherfliegen “ wird als Sonderfall der Opposition Nicht-Iterativität/ Iterativität betrachtet. Als Marker der Iterativität traten auch die Vokalalternationen im Stamm auf, vgl. z.B. die Gegenüberstellung von kurzen bzw. reduzierten und langen bzw. nicht reduzierten Vokalen (lěsti ,klettern' - laziti ,umherklettern', lobŭzati ,küssen “ lobyzati ,mehrmals küssen") und die Alternation des primären und des sekundären Vokalismus des Stammes (nesti ,tragen“ - nositi, zu tragen pflegen', vesti ,führen“ voditi, hierhin und dorthin führen'). Das Auftreten des Suffixes - $a$ - für den Ausdruck 
der Iterativität wird manchmal von einigen Alternationen begleitet, vgl. prositi, bitten “ prašati ,betteln". Die indeterminierten Verben vom Typ nositi ,zu tragen pflegen", choditi ,zu gehen pflegen', jězditi, zu fahren pflegen', die kein iteratives Suffix - $a$ haben, aber iterative Bedeutung aufweisen, bilden im Altrussischen die sog. sekundären Iterativa mit dem produktiven Suffix - $a$-: našati, chaždati, jězžati.

Von den perfektiven verba simplicia vom Typ pasti (<*padti), fallen“ und von ihren präfigierten Derivaten vom Typ upasti ,fallen“ werden mit den gleichen formalen Mitteln die abgeleiteten Imperfektiva vom Typ padati bzw. upadati gebildet. Diese Imperfektiva weisen die Neutralisierung der Opposition Nicht-Iterativität/Iterativität auf. Die imperfektive Bedeutung schließt die iterative Bedeutung als Sonderfall ein. Daraus folgt, dass die Opposition Nicht-Iterativität/Iterativität und die Opposition Imperfektivität/Perfektivität verschiedene Domänen haben und einander ergänzen. Sie sind miteinander durch eine komplementäre Distribution verbunden.

\section{Entwicklung der Opposition Perfektivität/Imperfektivität}

3.1 Aspektuelle Indifferen $z$ bei aterminativen und terminativen Verben im Frühaltrussischen

Die neuen slavischen Aspekte als jüngere Schicht der aspektuellen Differenzierung weisen im Frühaltrussischen bestimmte Besonderheiten auf, die für das Übergangsstadium vom aspektlosen Verbalsystem des Frühgemeinslavischen zum grammatikalisierten Aspektsystem des modernen Russischen charakteristisch sind (vgl. Bermel 1995: 345). Die Herausbildung der neuen slavischen Aspekte begann in der gemeinslavischen Epoche und war zu Beginn der historischen Überlieferung bereits relativ fortgeschritten. In den ältesten altrussischen Denkmälern hatten die meisten Verben eine bestimmte aspektuelle Bedeutung des pf. oder des ipf. Aspekts. Jedoch blieben zahlreiche Verben im Altrussischen noch aspektindifferent und konnten sowohl perfektiv als auch imperfektiv gebraucht werden.

Die aterminativen verba simplicia vom Typ idti ,gehen', ěchati ,fahren', nesti ,tragen', viděti ,sehen', slyšati ,hören', suditi ,richten', grěšiti ,sündigen', die in der russischen Sprache der Gegenwart imperfektiv sind, verhaiten sich im Altrussischen noch unentschieden zum Aspekt, vgl. die imperfektive (bzw. präsentische) Interpretation dieser Verben im Beispiel (1) und die perfektive (bzw. futurale) Deutung solcher Verben im Beispiel (2).

(1) Igoř ědetŭ po Boriðevu (Igorlied aus dem 12. Jh.) ,Igor fährt durch Boritschev"

(2) Ne šli otroka jědu [= prijedu] samŭ i dve grivny vezu [= privezu] (Birk.-Inschr. des 13. Jh.) ,Schicke nicht den Diener, ich werde selbst fahren und werde zwei Grivnas mitnehmen

Die terminativen verba simplicia vom Typ dati ,geben', pasti ,fallen', kupiti ,kaufen', lišiti ,wegnehmen', sěsti ,sich (hin)setzen', leči , sich (hin)legen', die in der russischen Sprache der Gegenwart perfektiv sind, waren im Altrussischen nicht auf den perfektiven 
Aspekt (Beispiel (3)) beschränkt, vgl. die Verwendung des Verbs kupiti ,kaufen ' im imperfektiven Kontext (mit Phasenverb) im Beispiel (4):

(3) učenici bo ego ošñli běachu vŭ gradŭ, da brašino kupjatı̆ (Ostr.-Ev. 1056-1057) ,seine Schüler waren in dic Stadt gegangen, um Nahrung zu kaufen *

(4) počachomŭ kupiti chlebŭ (Novg. -Chr. 13.-14. Jh.) , wir haben angefangen, Brot zu kaufen" (d.h. , wir sind Brot kaufen gegangen")

Die entsprechenden Imperfektiva vom Typ dajati oder davati, geben ' waren zwar schon in den ältesten Denkmälern des Russischen vorhanden, aber sie wurden selten verwendet. Prof. P. S. Kuznecov, ein aufmerksamer Forscher des Altrussischen, registriert einige Beispiele mit imperfektivem Gebrauch des Verbs pasti,(hin)fallen' bis zur Hälfte des 19. Jh. Solche Beispiele wurden sogar bei A. S. Puškin gefunden (Kuznecov 1953: 245-246).

Die präfigierten Verben vom Typ vŭteči ,münden, sich ergießen', die im modernen Russischen perfektiv sind und deshalb keine Präsensbedeutung aufweisen können, waren im Altrussischen aspektindifferent und konnten in Kontexten auftreten, die als imperfektiv bzw. präsentisch gelten:

(5) A Dněprŭ vtečet $[=$ tečetǐ $]$ v Pontǐskoe more (Laur.-Chr. 1377)

,Aber der Dnepr mündet ins Schwarze Meer‘

Die spätere Akademische Redaktion und die Radzivil-Chronik geben in diesem Beispiel eine eindeutig imperfektive präsentische Form tečet ̌̆ an. Die Form poteče im Beispiel (6) aus der Laurentius-Chronik (1377) wird durch die eindeutig imperfektive präsentische Form tečetǐ im Beispiel (7) in der Hypatius-Chronik (um 1425) ersetzt.

(6) Dněprŭ bo poteče (tİ) iz Okovĭskago lěsa (Laur.-Chr. 1377)

,Der Dnepr aber entspringt aus dem Okov-Wald ${ }^{*}$

(7) Dněprŭ bo tečet ĭ iz Vol(o)kovǐskag(o) lěsa (Hypat.-Chr. um 1425)

,Der Dnepr aber entspringt aus dem Vol(o)kov-Wald“

Die Präfixe solcher Verben treten im Altrussischen nicht als Marker der Perfektivität, sondern als Marker der Terminativität (oder der Grenzbezogenheit) auf (vgl. Karavanov 1992: 106-107).

\subsection{Die Paradigmen der sekundären Imperfektivierung im Frühaltrussischen}

Das Ausgangssystem der aspektuellen Oppositionen bilden im Altrussischen die Modelle der sekundären Imperfektivierung mit den produktiven Imperfektivierungssuffixen $-a-$ vom Typ otŭpasti (<*otŭpadti) - otüpadati ,ab-/wegfallen' und -ja-vom Typ obèliti oběljati ,weißwaschen', vŭskrěsiti - vŭskrěšati (<*vŭskrěsjati), wiederbeleben") sowie mit dem nichtproduktiven Imperfektivierungssuffix -va-vom Typ sŭviti - sǔvivati, zusammenrollen' und den Erwei terungen von -va-: -ava-, -ova-, -eva-vom Typ pokazati - pokazavati ,zeigen', privjazati - privjazovati , anbinden', vozderžati - vozderževati ,sich enthalten'. Diese Muster wurden dem Altrussischen vom Altslavischen vererbt. 
Die Imperfektivierungssuffixe waren nicht streng den einzelnen Klassen der Verbalstämme zugeordnet, vgl. z.B. die Kookkurrenz der Imperfektivierungssuffixe $-a$ - und -ja-: raschytiti - raschytati/raschiščati, veruntreuen', -ja- und -va-: podati - podajatil podavati, reichen“. Außerdem gab es auch Imperfektivierungsparadigmen mit neutraler aspektueller Bedeutung des (später perfektiven) Gegengliedes der aspektuellen Opposition: kupiti - kupovati ,kaufen', napisati - napisovati , an-/aufschreiben'. Das Aspektsystem war im Altrussischen folglich noch im Entstehen begriffen. Die ältesten Imperfektivierungsparadigmen waren noch nicht ausgeprägt, und noch relativ viele Verben waren aspektindifferent.

3.3 Die Verdrängung der Imperfektiva mit dem Suffix - $a$-/-ja- durch die Imperfektiva mit dem Suffix -yva-l-iva-

Am Anfang des 12. Jh. entsteht das neue Imperfektivierungssuffix -yva-/-iva- als Ergebnis der Reanalyse: umy-va-ti> um-yva-ti,(ab)waschen'. Der Gebrauch dieses Suffixes war zunächst stark eingeschränkt im Vergleich zu den produktiven Suffixen - $a$ und -ja-. Die Zahl solcher Imperfektiva mit dem Suffix -yva-/-iva- wuchs schnell an, und ab Mitte des 13. Jh. wurde dieses Suffix bereits produktiv. Die Imperfektiva mit diesem Suffix traten zuerst zusammen mit den anderen Imperfektiva auf. Die Zahl der Paradigmen mit mehreren miteinander konkurrierenden Imperfektiva nimmt zu, vgl. pristaviti - pristavljati/pristavlivati ,dazustellen', zapasti - zapasati/zapasyvati ,Vorräte anschaffen', südělati - sŭdělovati/sŭdělyvati ,machen, tun', sŭkupiti - sŭkupati/ sŭkupljati/sǔkuplivati' , verbinden, vereinigen', otjagǔčiti - otjagǔčati/otjagŭčavati/ otjagǔčevati/otjagǔčivati, erschweren". Diese Imperfektiva werden parallel und ohne Bedeutungsunterschiede gebraucht. In den verschiedenen Novgoroder Urkunden des 14. Jh. sind im gleichen Text die Formen pristavljati und pristavlivati registriert worden:

(8) a. Dvora ti ne zatvarjati, a pristavovŭ ne pristavljati (Novg.Urk. 1325-1326)

b. ...a dvora ti ne zatvorjati, a pristavovŭ ti ne pristavlivati (Novg.Urk. 1307) ,...und der Hof ist nicht zu verschließen, und es sind auch keine Wachen aufzustellen *

Besonders produktiv wurden die $-y v a-/-i v a$-Bildungen in der mittelrussischen Periode (15.-17. Jh.). Die Imperfektivierungssuffixe wurden nach dem Grad der Produktivität in folgender Weise neu gruppiert: (a) produktives monofunktionales Suffix -yva-/-iva- vom Typ perepisati - perepisyvati , abschreiben'; (b) weniger produktive Suffixe -a- und -ja: vyrubiti - vyrubati, abschlagen', podaviti - podavljati, unterdrücken'; (c) nichtproduktives Suffix -va- und die Ableitungen von ihm: -ava-, -eva-, -ova- vom Typ otkryti otkryvati, öffnen‘. Viele Verben bilden im Mittelrussischen die parallelen Imperfektiva mit dem Suffix -a-l-ja- vom Typ ispravljati und mit dem Suffix -yva-/-iva-vom Typ ispravlivati, verbessern'. Im Laufe der Sprachentwicklung verdrängen die sekundären Imperfektiva mit dem Suffix -yva-/-iva- die alten Bildungen mit den produktiven Suffixen - $a$ - und -ja-, vgl. ukladyvati anstatt ukladati, einpacken', utaivati anstatt utajati ,verbergen'. Die Reichweite der sekundären Imperfektiva mit dem Suffix -yva-/-ivaübersteigt im Mittelrussischen bei weitem deren Gebrauch im modernen Russischen, vgl. 
(9) i tem dei dostalnym ljudem ta Anna i syn ee Ivan ugraživajut (jetzt = ugrožajut) (Lesungen 1916) ,und den verbliebenen Leuten drohen angeblich diese Anna und ihr Sohn Ivan"

Erst in der neurussischen Zeit (ab 18. Jh.) werden die Imperfektiva mit dem Suffix -yva-/-iva- vom Typ ispravlivati, verbessern', ugraživati ,drohen' zugunsten der Imperfektiva mit dem Suffix -a-/-ja- vom Typ ispravljati, ugražati allmählich beseitigt. Dieser Prozess ist mit der Ausprägung der Aspekte und der Unifizierung der Aspektparadigmen verbunden. Die binären Aspektparadigmen mit nur einem einzigen Imperfektivum setzen sich gegenüber den Aspektparadigmen mit mehreren Imperfektiva durch. Erhalten geblieben sind im modernen Russischen nur wenige doppelte Imperfektiva, manchmal mit stilistischer Differenzierung, vgl. vyskrebat'/vyskrebyvat' , abkratzen', zagotovljat'/zagotavlivat', vorbereiten ', odarjat' (hoher Stil)/odarivat' , beschenken'.

\section{Kookkurrenz und Konkurrenz der alten indoeuropäischen und der neuen slavischen Aspekte. Schwund der alten indoeuropäischen Aspekte}

\subsection{Verlust des altrussischen Perfekts}

Eine wesentliche Neuerung in der Entwicklung der aspektuell-temporalen Formen im präteritalen Bereich des altrussischen Tempussystems war die Ersetzung der alten synthetischen Tempora, d.h. des Imperfekts und des Aorists, durch das neue $l$-Präteritum und dementsprechend der alten indoeuropäischen Aspekte durch die neuen slavischen Aspekte. Der Schwund des Hilfsverbs byti, sein' im Präsens und die damit verbundene Verschiebung der Bedeutung des $l$-Perfekts in Richtung Präteritum bildeten im Altrussischen den Ausgangspunkt für die Verdrängung der synthetischen präteritalen Paradigmen des Aorists und des Imperfekts durch das analytische Paradigma des neuen l-Präteritums. Das altrussische Perfekt wurde periphrastisch gebildet: Es setzte sich zusammen aus dem Partizipium praeteriti activi auf $-l$ - und den flektierten Präsensformen des Hilfsverb byti, sein'. Das altrussische Verb hatte zuerst im Standardgebrauch keine Personalpronomina: Die Kategorie der Person wurde durch die verbalen Endungen ausgedrückt. Die Personalpronomina wurden nur appositiv oder kontrastiv verwendet. Die Formen des Hilfsverbs byti , sein " wurden durch die Personalpronomina zuerst in der 3. Person, später auch in der 1. und in der 2. Person ersetzt. Die Entwicklung im Altrussischen in diesem Bereich kann man als Drei-Phasen-Prozess darstellen: (1) dalŭ jesi wörtlich ,gegeben hast", (2) ty dalŭ jesi, du hast gegeben', (3) ty dalŭ ,du gabst' (Isačenko 1976 [1939]: 16). Die häufigere Verwendung der Personalpronomina steht im Zusammenhang mit der Herauskristallisierung des $l$-Partizips als einziger Form der Vergangenheit: Der Verlust des Hilfsverbs byti ,sein' im Präsens machte es notwendig, die Kategorie der Person durch Personalpronomina zu manifestieren. Parallel mit dem Schwund des Auxiliars byti, sein' im Präsens findet eine Verschiebung der Bedeutung der l-Konstruktion bei terminativen (= grenzbezogenen) Verben vom Typ umerlü (jestǐ) von der ursprünglich perfektischen, d.h. der statalen Bedeutung (,er ist gestorben " = ,er ist tot ${ }^{\circ}$ ) (s. Beispiel (10)a) auf die aktionale Bedeutung einer vergangenen Handlung, d.h. des Präteritums als Tempus narrativum (,er starb') (s. Beispiel (10) b) statt. 
(10) a. Kon' umerlŭ (jesť̆) a ja živŭ (Russk. Pr. aus dem 11. Jh.)

,Das Pferd ist tot, ich aber lebe*

b. Vladyka rizkij umirl $\breve{u}$ (Smolensk.Urk. 1229)

,Der Erzbischof von Riga starb“

Die Verwendung der einst rein perfektischen $l$-Periphrase bei verba terminativa in präteritaler Funktion bildete die Voraussetzung für die Ausdehnung der $l$-Konstruktion auf verba aterminativa. Die $l$-Periphrase kann nur bei grenzbezogenen Verben ein echtes Perfekt sein. Bei nichtgrenzbezogenen Verben bezeichnet die 1-Konstruktion eine Hand-

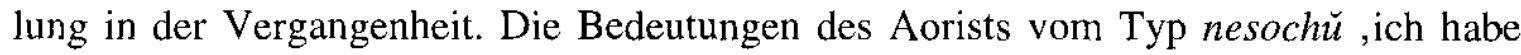
getragen " und der $l$-Periphrase vom Typ neslŭ jesm $\check{l}$, ich habe getragen" bei nichtterminativen Verben waren identisch: Beide Formen bezeichneten einen rein präteritalen Prozess (vgl. Sadnik 1966: 22). Das $l$-Präteritum tritt damit in Konkurrenz zu den synthetischen präteritalen Formen des Aorists und des Imperfekts, die ebenfalls präteritale Funktion hatten.

\subsection{Verschiebungen in der Aspektzuweisung bei synthetischen präteritalen Tempora}

Außer der Entwicklung des $l$-Präteritums selbst hat die Ausprägung der neuen slavischen Aspekte wesentlich zum bevorzugten Gebrauch des $l$-Präteritums beigetragen. Im Frühaltrussischen existierten im präteritalen Bereich die alten indoeuropäischen und die neuen slavischen Aspekte nebeneinander, vgl. das imperfektive Imperfekt vom Typ idjach $\breve{u}$,ich ging', das perfektive Imperfekt vom Typ otidjachŭ ,ich ging (öfter) fort', der perfektive Aorist vom Typ otidoch $\breve{u}$, ich bin weggegangen" und der imperfektive Aorist vom Typ idoch $\breve{u}$, ich bin gegangen“. Mit der Ausprägung der neuen slavischen Aspekte im Laufe der Sprachentwicklung wurden die Formen des imperfektiven Aorists und die des perfektiven Imperfekts beseitigt.

In den historisch ältesten Imperfektivierungsparadigmen vom Typ postaviti postavljati ,stellen' war im Frühaltrussischen (genauso wie im Altslavischen, vgl. Kølln 1958: 310) der imperfektive Aorist nicht belegt: postaviša (= pf. Aorist) , sie haben gestellt" vs. postavjachu(tĭ) (= pf. Imperfekt), sie haben (öfter) gestellt" und postavljachu(ť) (= ipf. Imperfekt), sie stellten'. Der imperfektive Aorist wurde nur von bestimmten aspektindifferenten verba simplicia des Typs idti ,gehen' (idoch $\breve{u}$, ich bin gegangen') (vgl. Rủžička 1957: 97-100) gebildet. Das perfektive Imperfekt (vom Typ postavjachu(ť̌), sie haben (öfter) gestellt') trat hauptsächlich im sogenannten iterativperfektiven Kontext (in der Terminologie von Ju. S. Maslov (1984 [1954]: 119) auf, d.h. bei der Bezeichnung der Wiederholung abgeschlossener Handlungen in der Vergangenheit, vgl. das folgende Beispiel aus der Laurentius-Chronik:

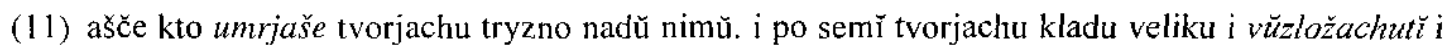
na kladu mertveca. sožlżachu. i posem ̌ sobravše kosti. vložachu v sudinu malu i postavjachu na stolpě na putechŭ... (Laur.-Chr. 1377)

, wenn einer starb, veranstalteten sie für ihn ein Gedenkfeier, danach errichteten sie einen großen (Holz)Stoß, legten den Leichnam darauf und verbrannten ihn; später sammelten sie die Knochen, legten sie in ein kleines Gefäß und stellten es auf eine Stelle am Wege...' 
In den späteren Redaktionen dieses Textes (Akademische Redaktion des 15. Jh. und Radzivil-Chronik Ende des 15. Jh.) werden einige Formen des perfektiven Imperfekts (umrjaše, sožlžachu, vložachu) bereits durch die Formen des imperfektiven Imperfekts (umiraše, sožigachu, vlagachu) substituiert. Im Laufe der Entwicklung wurde das perfektive Imperfekt vom Typ postavjachu(ť) , sie haben (öfter) gestellt' durch das imperfektive Imperfekt vom Typ postavljachu(ť $)$, sie stellten'vollständig ersetzt. Der Aorist wird fortan nur von perfektiven Stämmen und das Imperfekt nur von imperfektiven Stämmen gebildet. Die Opposition Aorist/Imperfekt vom Typ postaviša , sie haben gestellt ${ }^{*}$ - postavljachu(ťr), sie stellten ' und die Opposition präfigiertes Verb im $l$-Präteritum/dessen imperfektive Ableitung vom Typ postavili (sut') , sie haben gestellt' - postavljali (sut'), sie stellten' hatten die gleichen aspektuellen Stämme und wurden deshalb vom Standpunkt der aspektuellen Bedeutung gleichgestellt. Der Aorist bekommt folglich die Bedeutung des pf. A. und das Imperfekt die Bedeutung des ipf. A.

Mit der Etablierung der Perfektivierungsparadigmen vom Typ pisati - napisati ,schreiben' bekommen die präfigierten Formen des $l$-Präteritums vom Typ napisali (sut') , sie haben geschrieben' und des Aorists vom Typ napisaša ,sie haben geschrieben' die Bedeutung des pf. A., und die nicht präfigierten Formen des $l$-Präteritums vom Typ pisali (sut'), sie schrieben " und des Imperfekts vom Typ pisachu(tǐ), sie schrieben“ erhalten die Bedeutung des ipf. A. Die Opposition Imperfekt/Aorist vom Typ pisa-

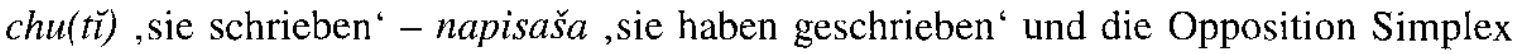
im $l$-Präteritum/dessen präfigierte Ableitung vom Typ pisali (sut') , sie schrieben “napisali (sut'), sie haben geschrieben ' hatten wie bei den Imperfektivierungsparadigmen die gleichen aspektuellen Stämme. Damit war rein formal die eins-zu-eins-Beziehung zwischen den alten indoeuropäischen und den neuen slavischen Aspekten, die semantisch sehr ähnlich waren, hergestellt. Die aspektuelle Information wird in den Formen des $l$-Präteritums nur einmal, mit Hilfe von Markern des pf. und des ipf. A., ausgedrückt, während in den synthetischen präteritalen Formen (des Aorists und des Imperfekts) die gleiche Information doppelt, mit Hilfe von Markern der alten und der neuen Aspekte, manifestiert wird.

\subsection{Die Konkurrenz zwischen dem $l$-Präteritum und den synthetischen präteritalen Paradigmen}

Die Konkurrenz zwischen den tempus- und aspektgleichen Paradigmen der synthetischen Formen und des $l$-Präteritums entscheidet sich schließlich zugunsten des $l$-Präteritums. Die Stämme des Aorists und des Imperfekts mit einer Vielzahl ihrer Varianten waren wesentlich komplexer als die Stämme des $l$-Präteritums. Die Stämme des $l$-Präteritums bestanden aus dem Infinitivstamm und dem Präteritalmarker $-l-$, vgl. z.B. nes-l-(i) (sut') , sie trugen". Die Stämme des Aorists und des Imperfekts waren aus dem Infinitivstamm, den Themavokalen - - - /-o-/-a-/-ja-/-o- und den Präteritalmarkern -ch-/-s-/-š-/-o- zusammengesetzt, vgl. z.B. die 3. Pers. Pl. des Imperfekts nes-ja-ch- $u$ - $(t \bar{l})$, sie trugen'. Das $l$-Präteritum drückte die neuen Aspekte aus, während der Aorist und das Imperfekt gleichzeitig die neuen und die alten Aspekte manifestierten, vgl. z.B. die 3. Pers. Pl. des Präteritums po$n e s-l-i$ (sut $\bar{l})$, sie haben getragen' und des Aorists po-nes-o-š- $a$, sie haben getragen'. Die 
neuen Aspekte sind in diesen Beispielen durch das Präfix po-repräsentiert. Die alten Aspekte sind durch den Themavokal - $o$ - und die Personalendung - $a$, die voneinander durch den Tempusmarker -š- getrennt sind, ausgedrückt. Das $l$-Präteritum hatte deutliche Vorteile gegenüber den synthetischen präteritalen Paradigmen in bezug auf die Entfaltungsmöglichkeiten der neuen slavischen Aspekte. Das $l$-Präteritum konnte sowohl von verba perfectiva als auch von verba imperfectiva gebildet werden, während der Aorist und das Imperfekt dazu neigten, sich auf perfektive bzw. auf imperfektive Verben zu beschränken, woraus sich die funktionale Identität der alten und der neuen Aspekte ergab. Die Differenzierung der Verben nach imperfektiven oder perfektiven Stämmen im $l$-Präteritum war wesentlich breiter angelegt als der Ausdruck der Aspekte mittels der Imperfekt- und Aoristendungen. Der Ausdruck der Aspekte wurde in den synthetischen präteritalen Formen nur auf den präteritalen Bereich beschränkt. Durch die $l$-Formen ergab sich die Möglichkeit der Ausdehnung der Aspekte auf alle temporalen und die nicht finiten Verbformen. Außerdem waren die Verbalendungen im Aorist und im Imperfekt stark beansprucht: Sie drüickten gleichzeitig die Kategorien der Person, des Numerus, des Tempus und des Aspekts aus. Die Ausbreitung des $l$-Präteritums (und der mit ihm verbundenen neuen slavischen Aspekte) und der Schwund der alten synthetischen Präterita (und der mit ihnen verbundenen alten indoeuropäischen Aspekte) waren damit vorprogrammiert.

\subsection{Ersetzung des Imperfekts und des Aorists durch das $l$-Präteritum}

Die Entwicklung im präteritalen Bereich des altrussischen Tempussystems verläuft gemäß dem Prinzip des natürlichen grammatischen Wandels in Richtung der Beseitigung der markierten Fragmente des Tempussystems (vgl. Wurzel 1994: 28-32). Das diese Entwicklung steuernde Prinzip des stufenweisen (oder geordneten) Markiertheitsabbaus, das von T. Vennemann (1988: 2-3) als diachrone Maxime formuliert ist, legt Reihenfolgen von Sprachveränderungen hinsichtlich eines Markiertheitsparameters fest.

In der ersten Etappe (bis 14. Jh.) gehen die markierten Paradigmen des Imperfekts, des Aorists und das mit ihnen verbundene Paradigma des Plusquamperfekts I verloren. In der zweiten Etappe (ab 15. Jh.) werden die markierten russischen Innovationen (das Plusquamperfekt II und das iterative Präteritum) abgebaut. Das Paradigma des $l$ Präteritums bleibt am Ende als einziges präteritales Paradigma erhalten.

Zuerst (im 12.-13. Jh.) verschwindet die Form des Imperfekts vom Typ nesjach $\breve{u}$ ,ich trug' (und die mit ihr verbundene Form des Plusquamperfekts I vom Typ bjachŭ $n e s l \breve{u}$, ich hatte getragen'), die gegenüber dem Aorist vom Typ nesoch $\breve{u}$, ich habe getragen" markiert war: Das Imperfekt hatte das Suffix -a-, das im Aorist nicht vorhanden war, und es drückte die Bedeutung der Durativität der Handlung aus. Danach

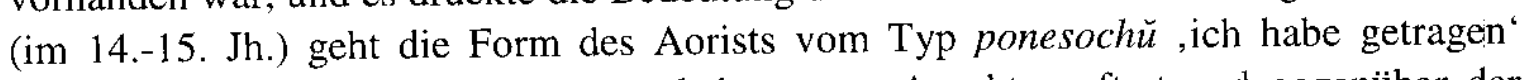
verloren, die als Träger der alten und der neuen Aspekte auftrat und gegenüber der Form des perfektiven $l$-Präteritums vom Typ poneslü (jesmĭ) als Träger nur der neuen slavischen Aspekte markiert war. Später verschwinden aus dem Sprachgebrauch die

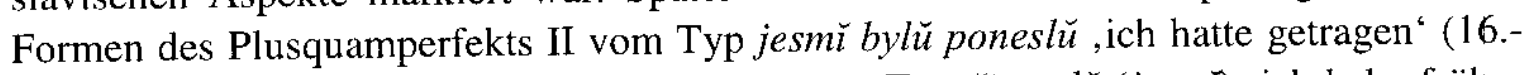
17. Jh.) und des sog. iterativen $l$-Präteritums vom Typ čityvalŭ (jesmí), ich habe früher (öfter) gelesen ' (19. Jh.), die gegenüber dem $l$-Präteritum markiert waren. 
Die aspektuell-temporalen Formen des Aorists und des Imperfekts wurden durch

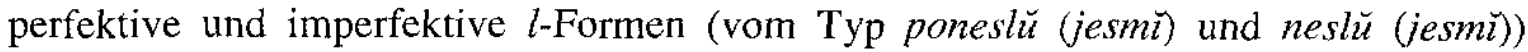
ersetzt. Es wird angenommen, dass das $l$-Perfekt vom direkten Diskurs via narrative Nebensätze in Richtung narrative Hauptsätze expandiert (vgl. Taube 1980: 121). Die Substitution des Aorists durch die $l$-Form nahm ihren Anfang in der 2. Person des Singulars. Diese kommunikativ wichtige Form der lebendigen dialogischen Rede war funktional prädestiniert für den Gebrauch des gegenwartsbezogenen Perfekts. Der Aorist und das Imperfekt waren dagegen Erzähltempora. Das $l$-Präteritum vom Typ neslŭ jesi ,du hast getragen" wurde verwendet, um die Form der 2. Pers.Sg. des Aorists vom Typ nese, du hast getragen" von der mit ihr identischen Form der 3. Pers.Sg. des Aorists vom Typ nese ,er hat getragen“ formal zu unterscheiden. Diese Entwicklung lässt sich anhand der sprachhistorischen Daten der altrussischen Schriftdenkmäler nachvollziehen. In der Laurentius-Chronik (14. Jh.) beträgt z.B. das Verhältnis der Verwendung des Perfekts zum Gebrauch des Aorists in der 2. Pers.Sg. durchschnittlich $75 \% \mathrm{zu}$ $25 \%$, während für alle anderen Formen ein Verhältnis entsprechend $5 \% \mathrm{zu} 95 \% \mathrm{zu}$ verzeichnen ist (Słoński 1926: 31-32). Später breitet sich die $l$-Form auf das gesamte Verbalparadigma aus und verdrängt die Formen des Aorists als Tempus narrativum gänzlich.

Die Entwicklung verlief gemäß dem Prinzip des natürlichen grammatischen Wandels in Richtung des Abbaus von Markiertheit, d.h. der Verdrängung der alten indoeuropäischen Aspekte (des perfektiven und des imperfektiven) durch die neuen slavischen Aspekte (= Opposition Perfektivität/Imperfektivität). Die aspektuell-temporalen Paradigmen des Aorists und des Imperfekts wurden durch perfektive und imperfektive $l$-Formen ersetzt. Die komplexen Endungen des Aorists und des Imperfekts wurden eliminiert und durch die Indikatoren des Genus und des Numerus im $l$-Präteritum ersetzt. Dadurch wurde eine beträchtliche Optimierung des Tempussystems im präteritalen Bereich erreicht. Man kann in diesem Zusammenhang in einem gewissen Sinne von einer Überwindung der Tempora durch die Aspekte sprechen (Braun 1947: 107).

Die Umbildung des altrussischen Tempussystems im präteritalen Bereich bestand darin, dass ein Synkretismus der Tempus- und Aspekt-Marker bei den Verbalendungen des Aorists und des Imperfekts durch die formale Trennung der aspektuellen und temporalen Funktionen beim $l$-Präteritum ersetzt wurde: Die temporale Funktion drückte das Suffix $-l-$ mit den nachfolgenden Endungen aus, und die aspektuelle Funktion wurde durch die Affixe des Stammes übernommen. Darin kann man die Wirkung des Prinzips der Uniformität/Distinktivität sehen, welches besagt, dass identische grammatische Bedeutungen durch identische Formen, unterschiedliche grammatische Bedeutungen durch unterschiedliche Formen wiedergegeben werden. Das war ein entscheidender Schritt zur Verselbständigung, d.h. zur Grammatikalisierung der Kategorie des Aspekts. Das neue $l$-Präteritum hat sich damit als einziges temporales Paradigma der Vergangenheit des Russischen konstituiert. Es übernimmt als universelles Vergangenheitstempus die Bedeutungen der verlorengegangenen Tempora: Die Form des imperfektiven $l$ Präteritums drückt die Bedeutung des alten Imperfekts aus, und die Form des perfektiven $l$-Prätertums vereinigt die Bedeutungen des Aorists, des Perfekts und des Plusquamperfekts. Mit dem Verlust des Aorists und des Imperfekts wird die alte aspektuelle Opposition nach dem Merkmal [+DURATIV]/[-DURATIV] als neue Aspektopposition nach dem Merkmal [-TOTAL]/[+TOTAL] uminterpretiert. Bei verba simplicia vom Typ birati 
,nehmen', pasti ,fallen' wird die durative Bedeutung als imperfektive (b̆rati), die nichtdurative Bedeutung als perfektive (pasti) umgedeutet. Bei präfigierten Verben werden die Durativa vom Typ izbiti ,prügeln' (vgl. biti ,schlagen, prügeln') und die NichtDurativa vom Typ ubiti, erschlagen, töten' formal und semantisch nicht unterschieden: Beide Verbtypen sind perfektiv geworden. Die aspektuelle Unterscheidung zwischen der statalen Bedeutung des Perfekts ([+STATISCH]) und der aktionalen Bedeutung des Aorists ([-STATISCH]) wird beseitigt: Das $l$-Präteritum übernimmt beide Bedeutungen.

\section{Umstrukturierung der alten Imperfektivierungsparadigmen und Verlust der Opposition Nicht-Iterativität/Iterativität}

\subsection{Ausdehnung der Domäne der Iterativität im Mittel- und Neurussischen}

Die alten Iterativierungssuffixe $-a-,-j a-$, die vom Altslavischen vererbt wurden, werden im Laufe der Sprachentwicklung unproduktiv. Die Häufigkeit der alten iterativen Bildungen mit diesen Suffixen lässt mit der Zeit immer mehr nach. Sie werden jedoch mit der Entstehung und der Verbreitung des Suffixes -yva-/-iva-wiederbelebt. In den ältesten russischen Denkmälern (z.B. in der Laurentius-Chronik) gibt es keine Simplizia mit dem Suffix -yva-/-iva- (vgl. Kuznecov 1959: 189). Auch zum Ende der altrussischen Epoche (13.-14. Jh.) tritt dieses Suffix nur bei präfjgierten Verben als Mittel der sekundären Imperfektivierung auf (vgl. Avanesov/Ivanov 1982: 271). Erst zum Anfang der mittelrussischen Periode (im 15. Jh.) dehnt sich dieses Suffix dann auf die verba simplicia aus. Es entstehen iterative Bildungen vom Typ dělyvati , mehrmals machen" (analog zu südělyvati ,machen'), die ab dem 16. Jh. sehr produktiv wurden.

$\mathrm{Zu}$ den verba simplicia mit iterativer Bedeutung gehören auch die Verben des Typs zastavlivati ,zu zwingen pflegen', in denen das Präfix (in diesem Fall za-) von der Wurzel (stav-) vom synchronen Standpunkt nicht mehr zu trennen ist. Die Imperfektiva des Typs zastavljati ,zwingen ' und die Iterativa des Typs zastavlivati ,zu zwingen pflegen“ stehen in der Opposition Nicht-Iterativität/Iterativität zueinander genauso wie die unpräfigierten Verben des Typs čitati, lesen“ - čityvati, zu lesen pflegen'. Die Opposition Nicht-Iterạtivität/Iterativität bilden die folgenden Simplizia mit den nur etymologisch trennbaren Präfixen: dopolnjat' ,ergänzen ' - dopolnivat' ,zu ergänzen pflegen ', ostavljat', lassen' ostavlivat' ,zu lassen pflegen ', pribavljat', zugeben , - pribavlivat' ,zuzugeben pflegen', ubavljat', verringern “ - ubavlivat', zu verringern pflegen', spuskat', loslassen ' - spuskivat' zu ,loszulassen pflegen‘. Die präfigierten Verben des Typs pristavljati und pristavlivati ,dazustellen` weisen im Unterschied zu den formal ähnlichen Bildungen mit den nur etymologisch trennbaren Präfixen des Typs zastavljati ,zwingen“ und zastavlivati ,zu zwingen pflegen' keine Opposition Nicht-Iterativität/Iterativität auf. Das sind korrelative Imperfektiva mit der gleichen Bedeutung. Traditionell wird diese Unterscheidung bei der Analyse der -yva-/-iva-Bildungen nicht beachtet, so dass die Iterativa und die Imperfektiva nicht getrennt voneinander behandelt werden (vgl. z.B. Gorškovia/ Chaburgaev 1997: 354-358, Tschernych 1977: 235-237, Nikiforov 1952: 113-129).

Iterativa mit dem Suffix -yva-/-iva- werden sogar von den abgeleiteten Imperfek- 
tiva (sowohl von den präfixlosen vom Typ davyvat' (< davat') ,zu geben pflegen ' als auch von den präfigierten vom Typ prodavyvat' (< prodavat', zu verkaufen pflegen') gebildet. Die alten sekundären Iterativa mit dem inzwischen unproduktiv gewordenen Suffix -a-/-ja- vom Typ našati ,zu tragen pflegen', chaždati ,zu gehen pflegen“, jězžati ,zu fahren pflegen' wurden durch die neuen Iterativa mit dem produktiven Suffix -yva-/ -iva- vom Typ nošivati, chaživati, jězživati ersetzt. Die alte Opposition der NichtIterativität/Iterativität vom Typ sěti ,säen“ - sějati ,zu säen pflegen' wird durch die neue Opposition vom Typ sějati ,säen“ - sěivati ,zu säen pflegen ' ersetzt. Die ursprünglich iterative Bildung vom Typ sějati wird im Zusammenhang mit dem Verlust der alten nichtiterativen Form vom Typ sěti als sekundäres Nicht-Iterativum in die neue Opposition aufgenommen.

\subsection{Entstehung der neuen temporalen Formen im Russischen: iteratives $l$-Präteritum und iteratives Präsens}

Das $l$-Präteritum iterativer Verben mit dem Suffix -yva-/-iva- war gut geeignet zur Wiedergabe der Bedeutung des alten Imperfekts, in dessen Semantik die Bedeutung der Wiederholbarkeit der Handlung enthalten war. Die Verbreitung des $l$-Präteritums iterativer Verben wurde offensichtlich durch den Untergang des alten Imperfekts gefördert.

Solche Präterita weisen usuelle oder habituelle Bedeutung auf, d.h. sie bezeichnen eine Handlung, die in der Vergangenheit gewöhnlich wiederholt wird.

(12) A Griško... u Ivana Koromyక̌eva žil, s klučami k gorodovym varotam chažival (Lesungen 1916) ,Und Griško wohnte bei Ivan Koromyšev, ging des öfteren mit den Schlüsseln zu den Stadttoren

(13) A komu što prodavyval vse v ljubov' a ne v oman (Domostroj 1908) ,Und wenn er jemandem etwas verkaufte, tat er es aus Liebe und nicht in betrügerischer Absicht"

(14) My lavlivali i eršej (I. A. Krylov) ,Wir haben auch des öfteren Kaulbarsche gefangen`

(15) Ne to na serebre - na zolote edal (A. S. Griboedov) ,Von Silber gar nicht zu reden, - von goldenen Tellern pflegte er zu essen

(16) „Strogost', strogost' i - strogost'“, govarival on obyknovenno (N. V. Gogol') ,„Strenge, Strenge und nochmals Strenge“, pflegte er gewöhnlich zu sagen“

Die Präteritalformen mit dem Suffix -yva-/-iva- dienten auch zum Ausdruck einer Handlung in ferner Vergangenheit (russ. davnoprošedšee vremja ,längstvergangene Zeit"). Die Kennzeichnung von etwas weit Zurückliegendem hatte mit der Bedeutung des Plusquamperfekts, das ein ausschließlich relatives Tempus war, nicht unmittelbar etwas zu tun. Die Form mit der Bedeutung der längstvergangenen Zeit war im Unterschied zum Plusquamperfekt ein absolutes Tempus. Die besondere temporale Bedeutung der längstvergangenen Zeit tritt schon in der mittelrussischen Periode (16,-17. Jh.) zutage. Dieses Tempus war besonders in der Literatursprache des 18. Jh. und der 1. Hälfte des 19. Jh. weit verbreitet. Das längstvergangene Tempus wird in der „Rossijskaja grammatika“ von M. V. Lomonossow (1755) und in der akademischen „Rossijskaja grammatika“ (1802) als Grundform der präteritalen Tempora betrachtet. Diese Form war damals sehr produktiv und gebräuchlich, besonders in der Umgangssprache. 
Die Form mit der Bedeutung der längstvergangenen Zeit bezeichnet gewohnheits+ mäßig ausgeübte oder oft wiederholte Handlungen, die vor langer Zeit in unregelmäßigen Zeitabschnitten stattfanden.

(17) Lug kašival istori Kuzma Barŭdatoj (Lesungen 1916) ,Die Wiese pflegte von jeher Kuzma Barǔdatoj zu mähen“

(18) citat' Karamzina ne budu: ja ego čityval i prežde (N. V. Stankevič) ,ich werde Karamzin nicht lesen; ich habe ihn ja früher viel gelesen "

In den Beispielen (17) und (18) wird die Bedeutung der Vorvergangenheit durch die Adverbialien istori, von jeher" und prežde ,früher" verstärkt. In den Beispielen (19) und (20) tritt die Bedeutung der längstvergangenen Zeit ohne kontextbedingte Verstärkung auf.

(19) - A vot kamin; Zdes ' barin sižival odin...(A. S. Puškin)

,- Und da ist der Kamin; hier saß der Gutsherr einst allein...

(20) - Vy znali Jakova Ivanoviča? - prodolžal ja

- Znavala-s - progovorila ona... (I. S. Turgenev)

, - Kannten Sie Jakov Ivanovic ? - fuhr ich fort

- Ja, er war mir damals bekannt, - sagte sie...

Die Bedeutung einer weit zurückliegenden, wiederholt ausgeführten Handlung kann durch die Partikel byvalo noch verstärkt werden:

(21) Byvalo, pisyvala krov'ju ona v al'bomy nežnych dev...(A. S. Puškin) ,Sie pflegte einst mit Blut in die Poesiealben zarter Jungfrauen (Verse) zu schreiben...

Die Partikel byvalo kann auch in Verbindung mit dem Präteritum gewöhnlichẹ Imperfektiva (Beispiel (22)), mit dem imperfektiven Präsens (Beispiel (23)) und mit dem perfektiven Präsens (Beispiel (24)) eine längst vergangene Handlung bezeichnen.

(22) Byvalo, vsja gubernija s"ezžalas' u nego, pljasala i veselilas' na slavu (I. S. Turgenev)

,Das ganze Gouvernement pflegte bei ihm zusammenzukommen, zu tanzen und sich köstlich zu amüsieren"

(23) Byvalo ona dvižetsja celyj den', kak choroso ustroennaja mašina (I. A. Gončarov) ,Sie bewegte sich gewöhnlich den ganzen Tag wie eine gut konstruierte Maschine

(24) Pridet, byvalo, i govorit: kakaja vaša žizn', izvozčiki ? (A. M. Gor'kij) ,Er kam oft zu uns und sagte: „Wie geht es euch, Kutscher ?““

Die Verbindung der Partikel byvalo mit Präsensformen imperfektiver und perfektiver Verben wird als praesens historicum interpretiert. Dieser Gebrauch verleiht der Handlung den Anstrich besonderer Lebendigkeit, ohne dabei ihren Vergangenheitscharakter zu ändern.

Das Präteritum mit dem Suffix -yva-l-iva- bezeichnet manchmal eine nicht ausgesprochen iterative Handlung in ferner Vergangenheit, vgl. die Beispiele (25) und (26) entsprechend mit und ohne Adverbialien, die auf eine längstvergangene Zeit hinweisen:

(25) A napered sego služival u Zacharija.... posle Zacharija služil u Mikity (Novg. Kn. 16.-17. Jh.) ,Und vorher hatte er bei Zacharij gedient, danach diente er bei Mikita

(26) Gosudar' chačival na pominkach pomirit'sja (Sad 1950)

,Der Fürst war damals fest entschlossen, sich auf der Gedenkfeier zu versöhnen " 
Im Kontext mit einer anderen Vergangenheitshandlung weist das Präteritum mit dem Suffix -yva-/-iva- die Bedeutung des Plusquamperfekts auf, d.h. es bezeichnet eine vorvergangene Handlung, vgl. die usuelle Handlung im Beispiel (27) und die einmalige Handlung im Beispiel (28).

(27) Se kupi...navolok... po ručei. gdě Evša rož' sěivalŭ (Dvin. Urk. 15. Jh.)

,Da hat er ein Grundstück, das am Bach lag, gekauft, wo Jevscha früher Roggen zu säen pflegte

(28) A prodali esmja tu zemlju..., čto kuplival brat že moj Boris... u Šichana (RIB 32: 1915) ,Und wir haben das Land wieder verkauft, was mein Bruder Boris bei Schichan gekauft hatte"

Das negierte Präteritum mit dem Suffix -yva-/-iva- drückt in der Regel eine kategorische, d.h. stark betonte Verneinung einer Vergangenheitshandlung aus:

(29) Da isstari byla dan' carej ruskich na Jur'evskoj derǐ̌ave, i toe dani ne plačivali mnogo let (RIB 15: 1894)

,Und es gab seit langem einen Tribut der russischen Zaren an die Jur'ev-Macht, und man zahlte diesen Tribut viele Jahre nicht"

(30) On rybačil tridcat' let i tri goda i ne slychival, čtob ryba govorila (A. S. Puškin) ,Er war dreiunddreißig Jahre lang Fischer und hatte noch nie einen Fisch sprechen hören "

Kontextelemente vom Typ nikogda ne, niemals, voobšče ne, überhaupt nicht", ni razu ne ,kein einziges Mal' unterstreichen die modale Bedeutung der kategorischen Verneinung:

(31) Tvoi posly našich poslov nikoli ne dožidyvalis' (RIB 16: 1897)

,Deine Abgesandten baben niemals auf unsere (Abgesandten) gewartet`

(32) Rešitel'no, ja nikogda podobnoj ženš̌iny ne vidyval (M. Ju. Lermontov) ,Ich habe entschieden noch niemals solch eine Frau zu Gesicht bekommen

Die Beispiele (33) und (34) drücken die Verneinung einer Einzelhandlung aus:

(33) I on dej emu chotel tot tovar otdati da i po sja mest ne otdavyval (RIB 15: 1894) , Und er wollte ihm angeblich diese Ware abgeben, aber bis jetzt hat er sie noch nicht abgegeben "

(34) I kreposti emu na sobja nikakie ne davyval i na pridanoj ne ženivalsja (RIB 17: 1898) ,Und er leistete ihm keinerlei Eid, und er heiratete nicht wegen Mitgift‘

In Fragesätzen mit der Partikel $l i$ drückt das Präteritum mit dem Suffix -yva-/-iva- einen prüfungsbedürftigen Punkt aus, nämlich ob eine Handlung irgendwann und wenigstens einmal stattgefunden hätte:

(35) A velel emu...obyskati..., chto $\mathrm{k}$ nej... priezžival ly i ce bival ly i mučival ly...i ce grablival ly... (RIB 2: 1875)

,Und er hat ihm befohlen...aufzuklären..., ob jemand bei ihr... angereist war und ob er sie geschlagen und gequält... und ausgeraubt hattc...

(36) Otvečai: pokradči esi ot knjaini begival li, i toe tatbu imyval li ? (AI 1841)

,Antworte: warst du von der Fürstin als Dieb weggelaufen, und hattest du das Dicbesgut bei dir? 
Die Bildungen mit dem Suffix -yva-/-iva- im Präsens drückten im Russischen die markierte Bedeutung des nichtaktuellen (= usuellen) Präsens aus, während die ihneh gegenüber stehenden Verbalformen ohne Suffix $-y v a-/-i v a-$ in bezug auf dieses Merkmal unmarkiert waren. Die Formen vom Typ kuplivajut $\check{l}$ sie pflegen zu kaufen?, davyvajut , sie pflegen zu geben' mit der Bedeutung des nichtaktuellen Präsens waren besonders in der Geschäftssprache des 16. und 17. Jh. verbreitet, vgl.

(37) Drugŭ druga zastavlivajutĭ bitisja (KRS 1647)

,Sie zwingen einander gewöhnlich, sich zu schlagen/miteinander zu kämpfen`

(38) I oni svoju ruchljad' i zapasy ostavlivajutŭ (SU 1649)

,Und sie lassen nach und nach ihr Hausgerät und die Vorräte zurück ‘

5.3 Natürlicher grammatischer Wandel im aspektuellen Bereich: Beseitigung der Imperfektiva und der Iterativa mit dem Suffix -yva-/-iva-im Neurussischen

Die Ausprägung der Aspekte setzt die Tendenz zur Umgestaltung der Aspektparadigmen gemäß dem semiotischen Prinzip der eindeutigen Zuordnung zwischen Form und Bedeutung in Gang. In Übereinstimmung mit diesem Prinzip findet ein Prozess der Neustrukturierung der Aspektparadigmen statt. Die Etablierung der Präfixe als Marker der Perfektivität und die Beseitigung der aspektuellen Indifferenz lösen die Verschmelzung der bis jetzt separaten Imperfektivierungsparadigmen für die aterminativen verba simplicia vom Typ mistiti (ipf. u. pf. A.) - mǔščati (ipf. A.) und für ihre präfigierten Ableitungen vom Typ otŭmĭstiti (pf. u. ipf.A.) - otŭm̌̌ščati (ipf. A.),(sich) rächen ‘ aus. Das Präfix otŭ-beim präfigierten Verb otŭmı̆stiti (pf. u. ipf. A.) ist desemantisiert, d.h. es hat seine konkrete Bedeutung (wie die der Abtrennung im Beispiel otŭpasti otüpadati ,ab-/wegfallen') verloren. Die Bedeutug des Verbs otümĭstiti (pf. u. ipf. A.) unterscheidet sich damit nicht von der Bedeutung der Simplizia mistiti (ipf. u. pf. A.) und mǔšcati (ipf. A.). (Anders ist die Lage beim präfigierten Verb otŭpasti ,ab-/wegfallen', dessen Bedeutung sich von der Bedeutung des Simplex pasti unterscheidet.) Das Simplizium mistiti ist das einfachste von allen vier Verben mit der gleichen lexikalischen Bedeutung. Alle anderen Verben sind direkte oder indirekte Ableitungen von diesem Verb. Mit der Grammatikalisierung des Präfixes otŭ- bekommt das Verb otümistiti perfektive Bedeutung. Die aspektuelle Korrelation seitens des perfektiven Verbs otŭmŭstiti wird nach dem semiotischen Prinzip der eindeutigen Zuordnung zwischen Form und Bedeutung natürlicherweise zum unmarkierten Simplizium mistiti (ipf. u. pf. A.) hergestellt. Das Simplizium mŭstiti erhält im Kontrast zur perfektiven Bedeutung des Gegengliedes der aspektuellen Opposition imperfektive Bedeutung. Alle anderen markierten Verben werden nach dem Prinzip des stufenweisen (oder geordneten) Markiertheitsabbaus (vgl. Vennemann 1988: 2-3) beseitigt. Stärker markierte Erscheinungen werden vor ihren schwächer markierten Pendants vom Wandel erfasst. Zuerst geht das stärker markierte präfigierte Verb otümǐšcati verloren, danach verschwindet das Verb müš́c das gegenüber dem Verb müstiti markiert war. Es entsteht auf diese Weise das neue binäre Perfektivierungsparadigma vom Typ mǔstiti (ipf. A.) - otŭmǐstiti (pf. A.), (sich) rächen‘.

Die aspektuellen Paradigmen der terminativen verba simplicia vom Typ kupiti (pf. u. ipf. A.) - kupovati (ipf. A.) und ihrer präfigierten Ableitungen vom Typ pokupiti (pf. u. 
ipf. A.) - pokupati (ipf. A.) unterliegen auch einer Fusion. Das terminative Simplizium kupiti wird als Perfektivum umgedeutet. Als imperfektive Entspechung zu kupiti tritt pokupati auf. Das ursprüngliche Imperfektivum kupovati zu kupiti mit dem alten unproduktiven Suffix -ova- und die präfigierte aspektindifferente Ableitung pokupiti werden beseitigt. In einigen Fällen wird das ursprünglich terminative Simplizium durch die präfigierte Ableitung ersetzt. In den alten Imperfektivierungsparadigmen vom Typ pasti (<* padti) (pf. u. ipf. A.) - padati (ipf. A.) und upasti (pf. u. ipf. A.) - upadati (ipf. A.) ,fallen" verschwinden das aspektindifferente Verb pasti und das Imperfektivum upadati. Die übriggebliebenen Glieder dieser Paradigmen bilden das neue Perfektivierungsparadigma vom Typ padati (ipf. A.) - upasti (pf. A.), fallen'. Das Präfix $u$ - in upasti mit der ursprünglichen Bedeutung der Bewegung nach unten hat die genau gleiche Bedeutung, die im Stamm pad- involviert ist. Das Verb upasti mit dem Präfix als Marker der Perfektivität wird gegenüber dem Simplizium pasti in diesem Fall bevorzugt. Das präfigierte Imperfektivum upadati ist komplexer als das präfixlose Imperfektivum padati und wird aus diesem Grund abgebaut. Analog dazu entsteht aus der Kontamination der alten Imperfektivierungsparadigmen strěliti (pf. u. ipf. A.) - strěljati (ipf. A.) und vystrěliti (pf. u. ipf. A.) - vystrěljati (ipf. A.), schießen“ durch die Tilgung des aspektindifferenten Verbs strěliti und des Imperfektivums vystrěljati das neue Perfektivierungsparadigma strěljati (ipf. A.) - vystrěliti (pf. A.) ,schießen'.

Die verba simplicia vom Typ biti, schlagen', die im Altrussischen eine Gegenüberstellung Nicht-Iterativität/Iterativität (biti (Nicht-Iter.) ,schlagen“ - bivati (Iter.) ,zu schlagen pflegen') aufweisen, verhalten sich nach dem Muster der aterminativen verba simplicia mit den Aspektparadigmen des Typs müstiti (ipf. u. pf. A.) - mǔšcati (ipf. A.) und ihren präfigierten Ableitungen des Typs otŭmistiti (pf. u. ipf. A.) - otŭmǔščati (ipf. A.), (sich) rächen“. Das Präfix po- in der Aspektopposition pobiti (pf. u. ipf. A.) pobivati (ipf. A.), schlagen“ wird grammatikalisiert. Das imperfektive Verb biti und das perfektive Verb pobiti werden dadurch bedeutungsgleich und treten als Aspektpartner in dem neuen Perfektivierungsparadigma biti (ipf. A.) - pobiti (pf. A.), schlagen' auf. Die anderen übriggebliebenen Glieder (pobivati und bivati) werden in dieser Reihenfolge beseitigt.

Die Paradigmen mit mehreren ursprünglichen Imperfektiva bzw. Iterativa unterliegen der Reduktion wie die ursprünglich binären Paradigmen, vgl. napisati (ipf. u. pf. A.) - napisovati/napisyvati (ipf. A.) , an-/aufschreiben' und pisati/pisovati (Nicht-Iter.) ,schreiben" - pisyvati (Iter.), zu schreiben pflegen'. Das Präfix na- in napisati hatte ursprünglich konkrete räumliche Bedeutung (= , an-/aufschreiben'). Das Präfix na- wird im Laufe der Sprachentwicklung desemantisiert (d.h. es verliert die konkrete räumliche Bedeutung) und grammatikalisiert. Ein imperfektives Simplex pisati und ein präfigiertes perfektives Verb vom Typ napisati sind mit der Grammatikalisierung (und der Desemantisierung) des Präfixes bedeutungsgleich geworden. Die Beseitigung der markierten Glieder dieser Opposition geschieht entsprechend dem Prinzip des geordneten (oder stufenweisen) Markiertheitsabbaus. Zuerst geht das Imperfektivum napisovati mit polyfunktionalem, d.h. relativ stärker markiertem Suffix - ova-verloren. Danach verschwindet die Form napisyvati mit monofunktionalem, d.h. relativ schwächer markiertem Suffix -yvaund schließlich wird die Form napisati (Präsens napisaju, ich schreibe') mit weniger markiertem Suffix $-a$ - beseitigt. Der Verlust präfigierter imperfektiver Glieder dieser 
Opposition geschieht in der russischen Literatursprache nicht früher als im 17. Jh. (vgl. Avanesov/Ivanov 1982: 276). Später (zum Ende des 19. Jh. (vgl. Vinogradov 1972: 431-433)) verschwinden die schwächer markierten präfixlosen Formen pisovati und pisyvati in dieser Reihenfolge. Die letzte Form existiert noch in den nichtkodifizierten Strata des Russischen (u.a. in der Umgangsprache). Es entsteht auf diese Weise das neue binäre Perfektivierungsparadigma vom Typ pisati (ipf. A.) - napisati (pf. A.), schreiben'.

Die Paradigmen dieses Typs sind im Unterschied zu den kontraikonischen Imperfektivierungsparadigmen ikonisch aufgebaut: Das semantisch markierte Perfektivum, das das semantische Merkmal der Ganzheitlichkeit oder der Totalität der Handlung aufweist, wird auch formal (durch ein Präfix) als markiertes Glied der Opposition ausgewiesen. Die Grenze zwischen Iterativa und Nicht-Iterativa war im Alt- und Mitte)russischen noch fließend. Die Form des Typs pisovati war z.B. nichtiterativ, während die Form dělovati iterativ war. Das Perfektivierungsparadigma vom Typ dělati (ipf. A.) - sŭdělati (pf. A.) ,tun, machen“ entsteht als Ergebnis der Verschmelzung des alten Imperfektivierungsparadigmas sŭdělati (pf. u. ipf. A.) - sǔdělovati/sŭdělyvati (ipf. A.) ,tun, machen“ und des Paradigmas der Nicht-Iterativität/Iterativität dělati (Nicht-Iter.) ,tun, machen'- dělovati/dělyvati (Iter.) ,zu tun pflegen‘.

Die anderen iterativen Bildungen werden im Laufe der Sprachentwicklung als nichtiterative Imperfektiva uminterpretiert. Dadurch entstehen die neuen Imperfektivierungsparadigmen mit sekundären Perfektiva. Die ursprünglich nichtiterative Form vom Typ sět i in der Opposition sěti (Nicht-Iter.), säen' - sějati (Iter.), zu säen pflegen' und die aspektindifferente Ableitung von ihr vom Typ zasěti in der Korrelation zasěti (pf. u. ipf. A.) - zasějati (ipf. A.), säen' verschwinden relativ schnell schon im Frühaltrussischen. Die übriggebliebene iterative Form des Typs sějati verliert ihre ursprüngliche iteratiye Bedeutung und wird als Imperfektivum aufgefasst. Die ursprünglich imperfektiye Ableitung zasějati wird im Zusammenhang mit dem Schwund des ursprünglichen aspektindifferenten Verbs zasěti als Perfektivum im Perfektivierungsparadigma sějati (ipf. A.) - zasějati (pf. A.) ,säen' reinterpretiert. Als sekundäres Imperfektivum zu zasějati tritt zaš̌vati im neuen Imperfektivierungsparadigma zasějati (pf. A.) - zasěvati (ipf. A.) ,säen' auf. Aus der Verschmelzung des ursprünglichen Imperfektivierungsparadigmas proč̌sti (pf. u. ipf. A.) - pročitati (ipf. A.), lesen' und des Paradigmas der Nicht-Iterativität/Iterativität č̌sti (Nicht-Iter.) ,lesen“ - čitati (Iter.) ,zu lesen pflegen' entsteht analog dazu das neue Perfektivierungsparadigma čitati (ipf. A.) pročitati (pf. A.) ,lesen“. Mit dem sekundären Perfektivum pročitati wird das neue Imperfektivierungsparadigma pročitati (pf. A.) - pročityvati (ipf. A.), lesen` gebildet. Das alte Verb pročıssti mit perfektiver Bedeutung verschwindet nicht, sondern wird in die nichtkodifizierten Strata verdrängt.

Die iterativen -yva-/-iva-Bildungen treten als produktive Klasse in nordrussischen Dialekten auf. Diese Mundarten weisen Iterativa von den abgeleiteten Imperfektiva des Typs davyvat' ,zu geben pflegen ' (< davat" ,geben') und des Typs perešivyvat" ,umzunähen pflegen' (< perešivat' ,umnähen') auf. Aus der Verdoppelung des Suffixes -yval-iva - ergibt sich das neue komplexe Suffix der Iterativität -yvliva-/-ivliva- vom Typ rasskazyvlivat", zu erzählen pflegen" und sprašivlivat", zu fragen pflegen" (vgl. Avanesov/Ivanov 1982: 177-178, Obnorskij 1953: 37-38). 
5.4 Der Abbau von Markiertheit im temporalen Bereich: Schwund der markierten Formen mit dem Suffix - yva-/-iva-

Das Präteritum mit -yva-/-iva- war gegenüber dem Präteritum ohne dieses Suffix formal und semantisch markiert. Die formale Komplexität des Präteritums mit -yva-/-iva- wurde durch das Vorhandensein dieses Suffixes gegeben. Semantisch wurde diese Form mittels der Bezeichnung der Iterativität als aspektuelle Hauptfunktion und des Ausdrucks der längstvergangenen Zeit als temporale Hauptfunktion gekennzeichnet. Aus der Konkurrenz zwischen dem markierten Präteritum mit dem Suffix -yva-/-iva- und dem unmarkierten Präteritum ohne dieses Suffix geht das unmarkierte Präteritum ohne das Suffix -yva-/-iva- als Sieger hervor. Die natürliche spachliche Entwicklung verläuft gemäß dem Prinzip des natürlichen grammatischen Wandels in Richtung auf die Beseitigung markierter Einheiten des Sprachsystems. Das markierte Präteritum mit dem Suffix -yva-I - iva- verschwindet genauso wie das Imperfekt, der Aorist und das Plusquamperfekt, die gegenüber dem einfachen Präteritum markiert waren. Ab Mitte des 19. Jh. wird der Gebrauch dieser Form allmählich reduziert. Zum Ende des 19. Jh. geht dieses Tempus in der Literatursprache völlig verloren. Im modernen Russischen wird dieses Tempus nur als stilistisches Mittel der Archaisierung des Textes in der schöngeistigen Literatur verwendet.

Die-yva-l-iva-Bildungen im Präsens mit der Bedeutung des nichtaktuellen Präsens, die gegenüber den Präsensformen ohne dieses Suffix markiert waren, verschwinden aus dem Sprachgebrauch noch früher, nämlich schon zur Mitte des 18. Jh. Damit ging auch die Opposition des nichtaktuellen und des aktuellen Präsens verloren. Solche Entwicklung war durch die Wirkung des Prinzips des natülichen grammatischen Wandels vorprogrammiert.

\section{Schlußfolgerungen}

Bezüglich der Strukturierung der Aspektualität im Frühaltrussischen wird die Hypothese von der Koexistenz der drei Typen aspektueller Oppositionen (die alten indoeuropäischen Aspekte, die alte slavische Opposition Nicht-Iterativität/Iterativität und die neuen slavischen Aspekte) aufgestellt. Die Entwicklung dieser drei Oppositionen verläuft gemäß dem Prinzip der typologischen Einheitlichkeit und Systematik morphologischer Systeme (Wurzel 1984: 174-175) in Richtung der Generalisierung der systemdefinierenden (= systemangemessenen) Struktureigenschaften, d.h. in Richtung der Beibehaltung der neuen slavischen Aspekte (= Opposition Imperfektivität/Perfektivität) und der Beseitigung der entsprechenden konkurrierenden Struktureigenschaften, d.h. der alten indoeuropäischen Aspekte (des imperfektiven, des perfektiven und des perfektischen) und der alten slavischen Opposition Nicht-Iterativität/Iterativität.

Die alten indoeuropäischen Aspekte wurden durch die neuen slavischen Aspekte ersetzt. Eine wesentliche Voraussetzung für die Umstrukturierung des vom Aitslavischen vererbten aspektuell-temporalen Systems war die Umkehrung der Markiertheitsrelationen zwischen dem Paradigma des neuen $l$-Präteritums und den Paradigmen des 
Imperfekts und des Aorists hinsichtlich der in diesen Paradigmen enthaltenen aspektuellen Merkmale. Im Verlauf der historischen Entwicklung verliert die analytische $l$-Form ihre ursprüngliche Funktion des alten perfektischen Aspekts und übernimmt die Bedeutung eines einfachen Präteritums. Die Verschiebung der Semantik der $l$-Form von der perfektischen zur präteritalen Bedeutung wird durch die Synthetisierung der $l$-Form, d.h. durch den Verlust des Auxiliars byti ,sein“ begleitet. Das neue $l$-Präteritum tritt damit in Konkurrenz zu den alten synthetischen Paradigmen des Imperfekts und des Aorists, die ebenfalls präteritale Funktion hatten. Das alte $l$-Perfekt war markiert (in bezug auf seine spezifische Bedeutung) gegenüber dem Imperfekt und dem Aorist. Das neue $l$-Präteritum, das nur die neuen slavischen Aspekte aufweist, wird als unmarkiert in bezug auf das Imperfekt und den Aorist aufgefasst, die weiterhin als Träger der alten und der neuen Aspekte funktionieren. In der Konkurrenz zwischen dem Paradigma des unmarkierten $l$-Präteritums und den markierten Paradigmen des Imperfekts sowie des Aorists gewinnt nach dem Prinzip des natürlichen grammatischen Wandels das unmarkierte $l$-Präteritum. Auf diese Weise werden die alten indoeuropäischen Aspekte beseitigt. Im Laufe der Sprachentwicklung verdrängt das unmarkierte $l$-Präteritum auch die anderen markierten präteritalen Paradigmen (des Plusquamperfekts I, des Plusquamperfekts II und des neuen russischen iterativen Präteritums).

Der natürliche grammatische Wandel, der durch die Ausprägung der neuen slavischen Aspekte (d.h. durch die Beseitigung der aspektuellen Indifferenz und vor allem durch die Etablierung der Präfixe als Marker der Perfektivität) ausgelöst wird, zielt auf den Abbau der markierten Fragmente des Aspektsystems, anders ausgedrückt auf die Optimierung des Aspektsystems, d.h. der Gestaltung der Aspektparadigmen in morphologisch sparsamer Art und Weise. Als Endergebnis der Verschmelzung der alten kontraikonschen Imperfektivierungsparadigmen entstehen die neuen ikonischen Perfektivierung\$paradigmen, die nach dem natürlichen Prinzip der eindeutigen Zuordnung zwischen Form und Bedeutung aufgebaut sind. In Übereinstimmung mit diesem Prinzip werden die aspektuellen Korrelationen mit mehrgliedrigen Imperfektiva in binäre Korrelationen umgewandelt, und die überflüssigen Imperfektiva werden abgebaut. Die Anzahl der Aspektparadigmen wird im Endergebnis der Umstrukturierung der Aspektparadigmen deutlich verringert. Das gesamte Aspektsystem wird dadurch straffer und übersichtlicher. Im Prozess der Restrukturierung der Aspektparadigmen verschwinden die sekundären Imperfektiva vom Typ pobivati, schlagen" und mit ihnen auch die Iterativa vom Typ bivati ,zu schlagen pflegen“ als inkompatibel mit der binären Organisation der Aspektparadigmen (nach dem Prinzip der Uniformität und der semantischen Transparenz). Damit geht auch die Opposition Nicht-Iterativität/Iterativität verloren. Die Oppositión Nicht-Iterativität/Iterativität wird folglich durch die Opposition Imperfektivität/ Perfektivität völlig verdrängt. Das geschieht in der zweiten Hälfte des 19. Jh. Die iterativen Bildungen werden entweder beseitigt (vgl. živati, zu leben pflegen', prašati ,zu bitten pflegen', rabotyvati ,zu arbeiten pflegen', édati/jadati, zu essen pflegen') oder werden als normale Imperfektiva reanalysiert (vgl. badati ,mit den Hörnern stoßen', sĕjati ,säen', čitati, lesen'). Außer den Bewegungsverben sind nur sehr wenige Iterativa (vom Typ byvat' ,zu sein pflegen') in der Literatursprache erhalten geblieben. Einige von ihnen wurden inzwischen in nichtkodifizierte Strata verdrängt, vgl. z.B. solche Verben wie pisyvat', zu schreiben pflegen', čityvat', zu lesen pflegen'. 
Die Geschichte der temporalen Formen mit dem Suffix -yva-/-iva- ist auf das Engste mit der Entwicklung der Aspekte verbunden. Der Übergang vom alten komplexen Tempussystem zum neuen reduzierten Tempussystem wurde durch das Aufkommen einer neuen Form der Vergangenheit, des sog. iterativen $l$-Präteritums, gekennzeichnet, das in einem gewissen Sinne als Ersatz für die verlorengegangenen Tempora (nämlich das Imperfekt und das Plusquamperfekt) diente. Das iterative $l$-Präteritum hat außerdem die neue Funktion der längstvergangenen Zeit übernommen. Die entsprechenden iterativen Bildungen im Präsens drückten eine usuelle Bedeutung aus und wurden den Standardformen des Präsens als Sonderform des nichtaktuellen Präsens gegenübergestellt. Diese beiden temporalen Formen mit dem Suffix -yva-l-iva-verschwinden als markierte Formen im Prozess der Umstrukturierung des Tempussystems, zuerst die Präsensformen (Mitte des 18. Jh.) und danach die präteritalen Formen (Ende des 19. Jh.).

Die Analyse der Entwicklung der aspektuellen und der temporalen Funktionen von $-y v a-$ - iva-Bildungen russischer Verben liefert die sich gegenseitig unterstützenden Evidenzen für den natürlichen grammatischen Wandel in diesen beiden Bereichen.

Von den drei miteinander konkurrierenden Aspektoppositionen (die alte slavische Opposition Nicht-Iterativität/Iterativität, die alten indoeuropäischen und die neuen slavischen Aspekte) bleibt am Ende nur eine einzige Opposition, nämich die der Imperfektivität/Perfektivität, erhalten. Das Russische hat damit radikale Veränderungen hinsichtlich des Abbaus der Markiertheit im Bereich des Aspektsystems erlitten, und diese Entwicklung hat die Umstrukturierung des Tempussystems entscheidend beeinflusst.

\section{Quellenverzeichnis}

AI $1841=$ Akty istoričeskie, sobrannye i izdannye Archeografičeskoju komissieju. T. I. Sankt Peterburg, 1841

Birk.-Inschr. des 13. Jh. = Birkenrinden-Inschriften des 13. Jh's aus Stara Russa. In: Arcichovskij, A.V.; Janin, V.L.: Novgorodskie gramoty na bereste. Moskva, 1978

Domostroj 1908 = Domostroj po Končinskomu spisku. Moskva, 1908

Dvin.Urk. 15. Jh. = Šachmatov, A.A: Issledovanija o dvinskich gramotach XV v. In: Issledovanija po russkomu jazyku. T. II, vyp. 3. Sankt Peterburg, 1903

Hypat.-Chr. um 1425 = Ipat'evskaja letopis'. In: Polnoe sobranie russkich letopisej II. Moskva, 1962

Igorlied aus dem 12. Jh. = Slovo o polku Igorevě. Moskva-Leningrad 1950

KRS 1647 = Kniga o ratnom stroenii - Učenie $i$ chitrost' ratnogo stroenija pechotnych ljudej. Moskva, 1647

Laur.-Chr. 1377 = Lavrent'evskaja letopis'. In: Polnoe sobranie russkich letopisej I. Leningrad, 1926-1927

Lesungen $1916=\check{C}$ tenija $v$ Obščestve istorii $i$ drevnostej rossijskich pri Moskovskom universitete. Kn. 2. Moskva, 1916

Novg.-Chr. 13-14 Jh. = Novgorodskaja (pervaja) letopis' po sinodal'nomu spisku XIII-XIV vv. In: Novgorodskaja charatejnaja letopis'. Moskva, 1964

Novg. Kn. 16.-17. Jh. = Novgorodskie zapisnye kabal'nye knigi $1591-1596$ i $1602-1603 \mathrm{gg} .1938$

Novg.Urk, um 1307/1325-1326 = Novgorodskie gramoty. In: Gramoty Velikogo Novgoroda i Pskova. Moskva- Leningrad, 1949

Ostr.-Ev. 1056-1057 = Ostromirovo evangelie. Sankt Peterburg, 1843

RIB 2: $1875=$ Russkaja istoričeskaja biblioteka . T. 2. Sankt Peterburg, 1875

RIB 15: 1894 = Russkaja istoričeskaja biblioteka. T. 15. Sankt Peterburg, 1894

RIB 16: 1897 = Russkaja istoričeskaja biblioteka. T. 16. Sankt Peterburg, 1897 
RIB 17: 1898 = Russkaja istoričeskaja biblioteka. T. 17. Sankt Peterburg, 1898

RIB 32: 1915 = Russkaja istoričeskaja biblioteka. T. 32. Petrograd, 1915

Russk,Pr. aus dem 11. Jh. = Russkaja Pravda, In: Karskij, E.F.: „Russkaja Pravda“ po drevnejšemu spisku. Leningrad, 1930

Sad $1950=$ P.A. Sadikov, Očerki po istorii opričniny. Moskva, 1950

Smolensk.Urk. 1229 = Smolenskaja gramota 1229 g. In: Smolenskie gramoty XIII-XIV vv. Moskva, 1963 SU 1649 = Sobornoe uloženie carja Alekseja Michajloviča. Moskva, 1649

\section{Literatur}

Avanesov, R.I.; Ivanov, V.V. (Red.) (1982): Istoričeskaja grammatika russkogo jazyka. Morfologija. Glagol. Moskau

Bermel, N. (1995): Aspect and shape of action in Old Russian. Russian Linguistics 19. 333-348

Braun, M. (1947): Grundzüge der slawischen Sprachen. Göttingen

Gorškova, K.V.; Chaburgaev, G.A. (1997): Istoričeskaja grammatika russkogo jazyka. Moskau.

Isačenko, A.V. (1976 [1939]): Poterja glagol'nych form v russkom jazyke. In: Isačenko, A.V.: Opera selecta. München, 1976. 12-20

Karavanov, A.A. (1992): K voprosu o charaktere kategorii predel'nosti drevnerusskogo glagola. Voprosy jazykoznanija 1992,6. 103-112

Kølln, H. (1958): Die Entstehung des slavischen Verbalaspekts. Scando-Slavica IV. 308-313

Kuznecov, P.S. (1953): K voprosu o genezise vido-vremennych otnošenij drevnerusskogo jazyka. $I m$ : Trudy Instituta Jazykoznanija AN SSSR II. Moskau. 220-252

Kuznecov, P.S. (1959): Očerki istoričeskoj morfologii russkogo jazyka. Moskau

Maslov, Ju.S. (1984 [1954]): Perfektivnyj imperfekt v drevncrusskom literaturnom jazyke. In: Maslov, Ju.S.: Očerki po aspektologii. Leningrad. 111-143

Mayerthaler, W. (1981): Natïrliche Morphologie. Wiesbaden

Nikiforov, S.D. (1952): Glagol, ego kategorii i formy v russkoj pis'mennosti vtoroj poloviny XVI veka. Moskau

Obnorskij, S.P. (1953): Očerki po morfologii russkogo glagola. Moskau

Růžička, R. (1957): Der Verbalaspekt in der altrussischen Nestorchronik. Berlin

Sadnik, L. (1966): Der Ersatz von Aorist und Imperfekt durch die 1-Periphrase, namentlich im Russischen. Anzeiger für slavische Philologie I. 16-30

Słoński, S. (1926): Tak zwane perfectum w językach słowiańskich. Prace Filologiczne X. 1-33

Taube, Moskau (1980): On the penetration of the perfect into the Russian narrative system. Russian Linguistics 5, 121-131

Tschernych, P.Ja. (1977): Historische Grammatik der russischen Sprache. Berlin

Venncmann, Th. (1988): Preference Laws for Syllable Structure and the Explanation of Sound Change. Berlin; New York; Amsterdam

Vinogradov, V.V. (1972): Russkij jazyk (grammatičeskoe učenie o slove). Moskau

Wurzel, W.U. (1984): Flexionsmorphologie und Natïrlichkeit. Berlin (= Studia grammatica XXI)

Wurzel, W.U. (1994): Grammatisch initilerter Wandel. Bochum (= Bochum-Essener Beiträge zur Sprachwandelforschung XXIII)

Wurzel, W.U. (1998): On Markedness. Theoretical Linguistics 24,1. 53-71

Wladimir D. Klimonow

Zcntrum für allgemeine Sprachwissenschaft,

Typologie und Universalienforschung

Jägerstr. 10-11

10117 Berlin

Germany

klimonov@zas.gwz-berlin.de 